\title{
FLOOD RISK AREAS SIMULATION USING SWAT AND GUMBEL DISTRIBUTION METHOD IN YANG CATCHMENT, NORTHEAST THAILAND
}

\author{
Haris PRASANCHUMI ${ }^{*}$ (D) Panuthat SIRISOOK ${ }^{2}$, Worapong LOHPAISANKRIT ${ }^{1}$
}

DOI: $10.21163 / G T \_2020.152 .04$

\begin{abstract}
:
Flooding problems have resulted in damage to urban and agricultural areas during the rainy season in the northeast of Thailand. Flood risk assessment at sub-catchment levels and proper explication of risk area can be guidelines for effective protection planning. This study aims to assess flood risk areas in the Yang catchment based on hydro-meteorological data between 2008-2016 by using the SWAT model for analyzing the maximum monthly discharge at each sub-catchment and fitted to the Gumbel distribution in order to evaluate flood risks in return periods of 2, 5, and 10 years. The results indicated that the calibrated the SWAT model can reasonably simulate discharge at the observed stations based on the statistical indicators such as $\mathrm{R}^{2}, \mathrm{RE}$, and $\mathrm{E}_{\mathrm{ns}}$. According to the Gumbel distribution methods, the western sub-catchments of the Yang catchment had a high level of flood risks. However, the other in the east sub-catchments were found to have lower levels of flood risks. The methods and results of this study can be useful tools and information for improving an understanding among stakeholders in the affected area in order to reduce damage from flooding in the future.
\end{abstract}

Key-words: Yang catchment, discharge, flood risk area, SWAT, Gumbel distribution.

\section{INTRODUCTION}

Discharge is the key factor that strongly causes the flood and it is mainly affected by climate and land use changes (Chung et al., 2018). In case that the discharge is much higher than the catchment capacity of rivers or reservoirs and the flow becomes uncontrollable, the excessive volume of the discharge may somehow cause the flood in which the damage levels depends on types of the area, and time period when the flood exists. The fact is that the discharge can be directly estimated at the observed stations that have been situated at many rivers through the past 10 years since the flood could cause a great loss of human's life and properties (Asgharpour \& Ajdari, 2011). In order to lessen and prevent the loss as well as to efficiently manage the limited natural resources in the future, the flood frequency and flood-risk areas have been analyzed and detected using several data indexes (Bhagat, 2017) as a tool to directly and indirectly define the conditions of the flood.

Over the last decade, mathematical models have been broadly used to assess the hydrologic processes existing around a catchment for the discharge studies and simulation for medium and small catchments (Haidu \& Ivan, 2016; Haidu et al., 2017; Strapazan \& Petruț, 2017). Particularly, SWAT (Soil and Water Assessment Tool) is a semi-distributed model interfaced with ArcGIS that has been popularly implemented since it is able to simulate physical characters of a catchment with a distributed-parameter system following the actual data from the target area and effective calculation procedure (Begou et al., 2016). The model is also able to simulate a site for the discharge assessment from the hydrological data and the data from the observed station and it gives the outcome that is very similar to the actual data.

\footnotetext{
${ }^{1}$ Faculty of Engineering, Rajamangala University of Technology Isan, Khon Kaen Campus, Khon Kaen, 40000, Thailand, * corresponding author haris.pr@ rmuti.ac.th; worapong.lo@ rmuti.ac.th ${ }^{2}$ Regional Irrigation Office 6, Khon Kaen, 40000, Thailand; banana60@gmail.com
} 
Actually, the discharge data is very necessary for a catchment since it is not only the standard to show the capacity of the catchment for water resource management, but it can be linked to define the flood risk index by analyzing the annually maximum flow rate with a Gumbel frequency distribution method (Györi et al., 2016; Bhagat, 2017). The result from this analysis method can define the severity levels and predict the time period when the flood is coming. This can definitely be one of the methods to decrease the loss after the flood.

In this case, Yang Catchment in the northeast of Thailand, a lot of people have mad use this river especially for agricultural purposes. Unfortunately, the flood has been regularly found around the Yang Catchment through many decades and it has a severe impact on the life quality of the local people in the area. The problem previously mentioned seems to be a negative consequence of the land use and climate changes so that the accurate estimation of the discharge as the source of the flood during the raining season (Ivan et al., 2018) as well as a quick data distribution to reach out all stakeholders will surely facilitate effective water resource management and prevent any problems that might come after the flood in the area. This study hence aims to investigate the maximum discharge with strong impact on the flood using the SWAT model together with a Gumbel frequency distribution method in order to predict and estimate the possibility rate of the flood in the regional river catchments. The result would be presented as spatial map in GIS and it would be able to decrease the impact of the flood on the local agriculture as well as a tool for either water management or lessen any problems coming after the flood in the future.

\section{STUDY AREA}

Yang Catchment is located at the eastern part of Chi Catchment and most of the area is flat and undulating covering 4,145 $\mathrm{km}^{2}$. Based on a 10-year climate data from the Thai Meteorological Department (during 2008-2016), the monthly average temperature can be $22.7-29.7{ }^{\circ} \mathrm{C}$. The rainy season typically starts from May to October and the average rainfall is about 1,200 $\mathrm{mm}$ per year. There are 2 discharge observed stations found in the area including the E54 and E92 as presented in Fig. 1(a). Most of the discharge will be found from June to May and the average annual discharge is 1,336 million cubic meter (MCM).

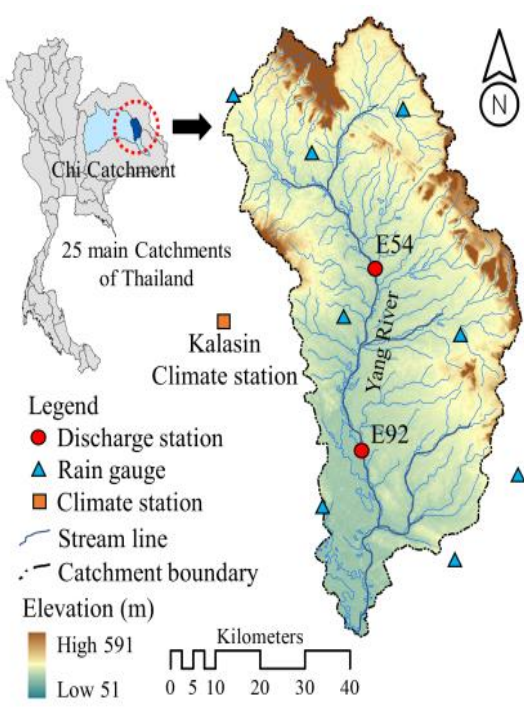

(a) Study area

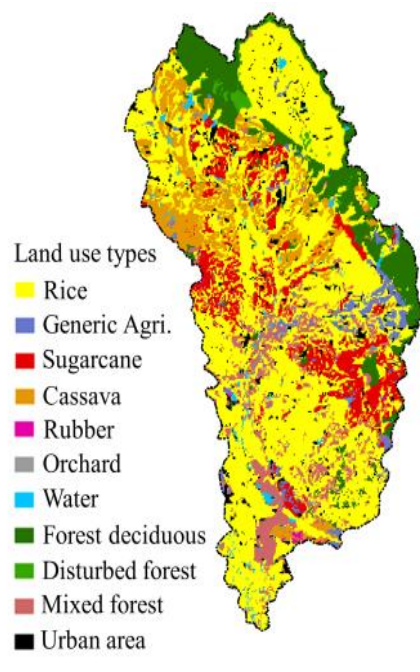

(b) Soil types map

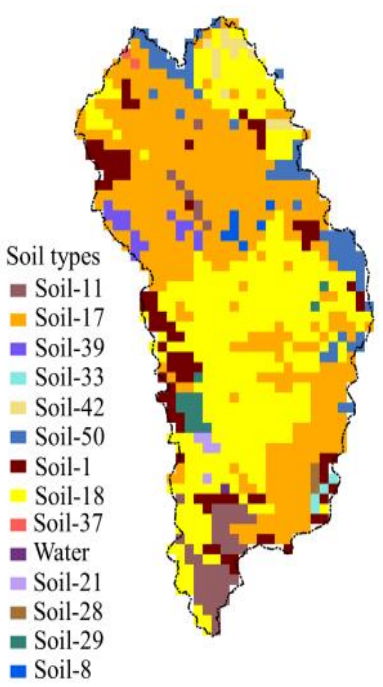

(c) Soil types map

Fig. 1. Study area and spatial data map. 


\section{METHODOLOGY}

\subsection{Sub-catchment area and discharge simulations}

\subsubsection{SWAT model and data collection}

The SWAT model (Arnold et al., 1998) is a semi-distributed hydrologic model purposively developed to estimate the hydrological conditions, the discharge form past to present, and predict any situations in the future (Maghsood et al, 2019). The feature of this model is that it can simulate watershed delineation to separate the whole area into sub-catchments (Pereiraa et al., 2016) and create the river route based on the user's need from digital elevation model (DEM) of each sub-catchment created by the model. This allows the user to know the discharge in each sub-catchment which is a great benefit for the spatial data analysis on the discharge from the regional catchments. In term of data calculation, the SWAT model principally considers any hydrological processes using a water balance equation as illustrated in Eq. (1) (Sajikumar \& Remya, 2018).

$$
S W_{t}=S W_{0}+\sum_{i=1}^{t}\left(R_{\text {day }}-Q_{\text {surf }}-E_{a}-W_{\text {seep }}-Q_{q w}\right)
$$

where, $S W_{t}$ was final soil water content $(\mathrm{mm}), S W_{0}$ was initial soil water content $(\mathrm{mm}), t$ was time (day), $R_{\text {day }}$ was rainfall on day $i(\mathrm{~mm}), Q_{\text {surf }}$ was surface water content on day $i(\mathrm{~mm}), E_{a}$ was evapotranspiration rate on day $i(\mathrm{~mm}), W_{\text {seep }}$ was groundwater water content on day $i(\mathrm{~mm})$, and $Q_{g w}$ was groundwater return to discharge on day $i(\mathrm{~mm})$.

The model requires the input data in order to create Hydrologic Response Units (HRUs) (Ning et al., 2015) and different parameters for the discharge calculation e.g. digital elevation model (DEM), climate and daily rainfall data (from 9 Stations as illustrated in Fig. 1(a)), different spatial data, and the discharge data from the observed stations for data calibration on the model's outcome as presented in Table 1. Samples of important spatial data were soil types and the land use as presented in Fig. 1(b) and Fig. 1(c) that the most of soil types consist of 2 types which are Soil-17 (sandy loam to sandy clay loam) and Soil-18 (similar like Soil-17 but increased by increasing in depth). The land contains low to moderate fertility. Regarding the land use, Yang Catchment is mostly used for agriculture or $75 \%$ of the area and a regular plant is rice. Meanwhile, $12 \%$ of the area is the forest zone and another $3.5 \%$ is the local community zone.

Spatial data for input to the SWAT model and for evaluate model accuracy.

Table 1.

\begin{tabular}{|c|c|c|c|}
\hline Data types & Periods & Scale & Source \\
\hline Digital Elevation Model (DEM) & 2015 & $30 \times 30 \mathrm{~m}$ & \multirow{4}{*}{$\begin{array}{l}\text { Land Development } \\
\text { Department }\end{array}$} \\
\hline Catchment boundary and river map & 2015 & $1: 50,000$ & \\
\hline Soil type map & 2015 & $1: 50,000$ & \\
\hline Land use map & 2015 & $30 \times 30 \mathrm{~m}$ & \\
\hline climate data & $2008-2016$ & Daily & \multirow{2}{*}{$\begin{array}{l}\text { Thai Meteorology } \\
\text { Department }\end{array}$} \\
\hline Rainfall data (9 Stations) & 2008-2016 & Daily & \\
\hline $\begin{array}{l}\text { Discharge data from } 2 \text { observed stations } \\
\text { (E54 and E92) }\end{array}$ & $2008-2016$ & Daily & $\begin{array}{l}\text { Royal Irrigation } \\
\text { Department }\end{array}$ \\
\hline
\end{tabular}

\subsubsection{Model calibration and validation}

The model calibration and validation were performed to assess the effectiveness of the outcome derived from the SWAT model (Kumar et al., 2017) to confirm its accuracy compared with the field data (Lin et al., 2015). These methods were done by comparing the discharge from 2 observed stations - E54 and E92 with the calculated result from the SWAT model specifically for the monthly scale. 
The calibration period was from 2008 to 2013 (6 years) and the validation period was from 2014 to 2018 (3 years). During this step, the model needed to adjust the hydrological sensitivity parameters (Fukunaga et al., 2015) that might have some impact on the discharge and 7 parameters were mentioned in this study including SOL_AWC, ESCO, ALPHA_BF, SLSUBBSN, GW_DELAY, SURLAG, and CH_N2. Additionally, 3 types of indexes were used for the model assessment consisting of Coefficient of Determination $\left(\mathrm{R}^{2}\right)$, Relative Error (RE), and Nash-Suttclife efficiency $\left(\mathrm{E}_{\mathrm{ns}}\right)$ as illustrated in Eq. (2)-(4), respectively.

$$
\begin{gathered}
R^{2}=\left(\frac{\sum_{i=1}^{n}\left(Q_{o i}-\bar{Q}\right)\left(Q_{s i}-\overline{Q_{s}}\right)}{\sqrt{\sum_{i=1}^{n}\left(Q_{o i}-\bar{Q}\right)^{2} \sqrt{\sum_{i=1}^{n}\left(Q_{s i}-\bar{Q}\right)^{2}}}}\right)^{2} \\
R E=\left(\frac{Q_{s}-Q_{o}}{Q_{o}}\right) \times 100 \\
E_{n s}=1-\left(\frac{\sum_{i=1}^{n}\left(Q_{o}-Q_{S}\right)^{2}}{\sum_{i=1}^{n}\left(Q_{o}-\overline{Q_{s}}\right)^{2}}\right)
\end{gathered}
$$

where $i$ was the data order, $n$ was number of total data, $Q_{o i}$ was the observed data at time $i, \bar{Q}$ was the average of all observed data, $Q_{s i}$ was the data from model at time $i$, and $\bar{Q}_{s}$ was the average from the model.

\subsection{Gumbel frequency distribution method}

Gumbel frequency distribution is a method that can be applied to find the extreme value distribution function (Pinherio \& Ferari, 2016; Parhi, 2018) in a variety of both hydrological and meteorological works such as the maximum flood or rainfall prediction (Olumide et al., 2013; Ganamala \& Kumar, 2017, ), etc. This technique is exactly applicable for the area with a short-term maximum discharge (Bhagat, 2017) and, this technique was used in Thailand to statistically study the flood risk at Yang Catchment under the climate changes in the future (Shrestha \& Lohpaisankrit, 2017). The equation to analyze the maximum flood in different return periods was depicted in Eq. (5).

$$
Q_{T}=\bar{Q}+K \sigma
$$

where $Q_{T}$ was maximum discharge in return period time $T, \bar{Q}$ was average maximum discharge, $K$ was frequency factor (see Eq. (6)), and $\sigma$ was standard deviation (see Eq. (7)).

$$
\begin{gathered}
K=\frac{Y_{T}-\bar{Y}_{n}}{S_{n}} \\
\sigma=\sqrt{\frac{\sum(Q-\bar{Q})^{2}}{N-1}}
\end{gathered}
$$

where $Y_{T}$ was reduced variable as seen in Eq. (8), and $S_{n}$ was reduced mean and reduced standard deviation respectively depending on the data number of year $N$, and $Q$ was annual maximum discharge. 


$$
Y_{T}=-\left[\ln \cdot \ln \cdot\left(\frac{T}{T-1}\right)\right]
$$

\subsection{Study procedure and flood risk area mapping}

The procedure of the flood frequency analysis and flood-risk area mapping at Yang Catchment was illustrated in Fig. 3 and the overview of all details were discussed in the sub-section 3.3.1-3.3.4.

3.3.1. Separating the sub-catchments: The sub-catchments were separated during the step of watershed delineation of the SWAT model (Swain et al., 2018) in which each sub-catchment could present the maximum discharge at the desired period and it chose to present the monthly data (the model already passed the calibration and validation method) so the result would be consistent with the discharge verification and calibration between the SWAT model and the observed stations.

3.3.2. Creating a relationship between the discharge and return period: The maximum discharges from each sub-catchment during 2008-2016 (9 years) was used to create a relationship between the flow rate and return period using a Gumbel frequency distribution method (Subyani, 2011). This method was resulted as an equation for the maximum discharge predication at different return periods $(2,5$, and 10 years respectively).

3.3.3. Calculating the flood frequency: The maximum discharge derived in the previous sub-section was processed to find the mean score of each sub-catchment as the standard value to define the severity levels of the flood and then the differences between the maximum discharge and the average maximum discharge of every return period were calculated.

3.3.3. Creating the flood-risk area map: The discharge derived from the equations at each different return period from each sub-catchment was converted to a shape file and prepared to put into ArcGIS Model in which the severity levels of the flood were based on the maximum discharge classified into different ranges (100 MCM) and each period was differentiated by the color intensity of each different sub-catchment made by the SWAT model. The result was presented as the spatial map.

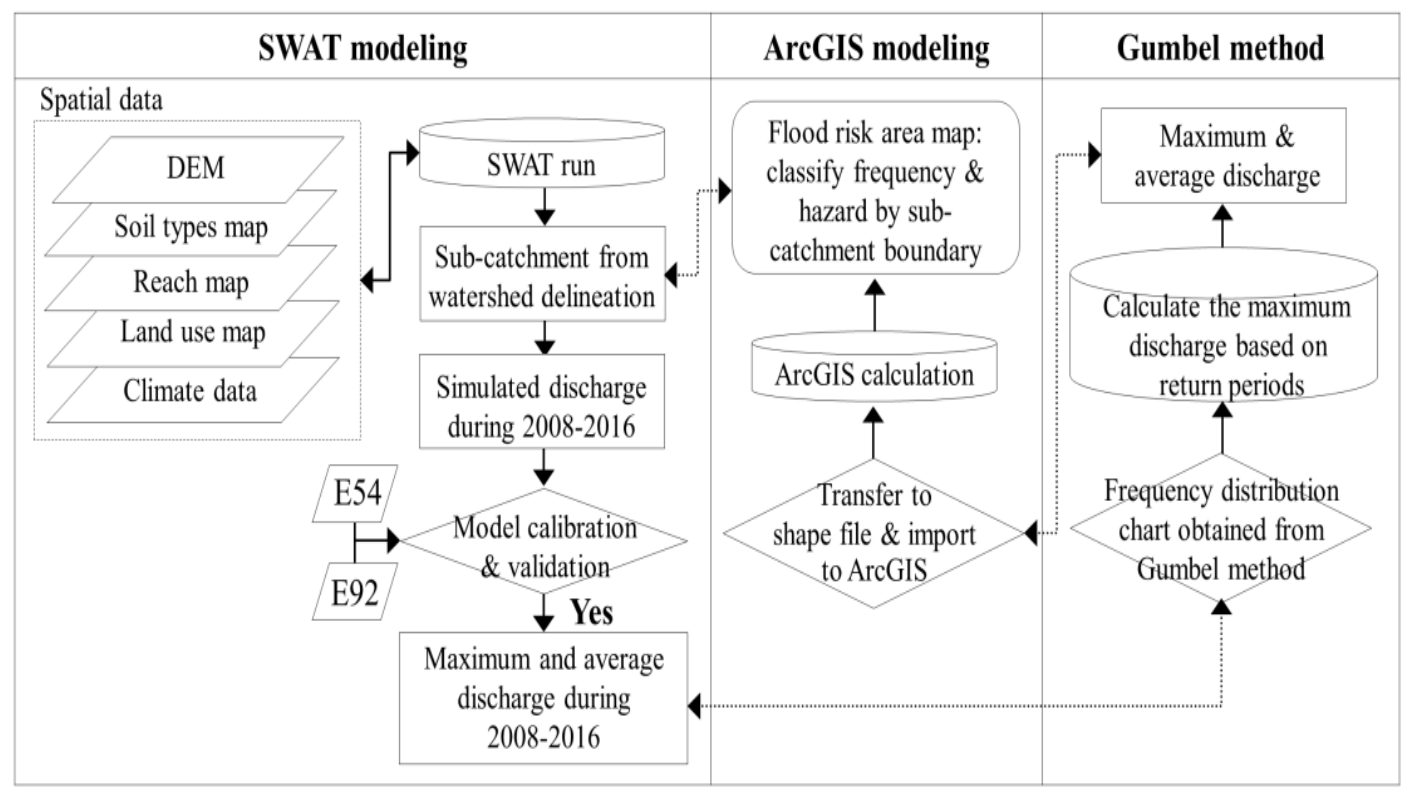

Fig. 3. Study procedure diagram. 


\section{RESULT AND DISCUSSIONS}

\subsection{Discharge analysis by SWAT}

The watershed delineation of Yang Catchment was resulted as 15 sub-catchments as presented in Fig. 4(a) and each of these sub-catchments was analyzed to define and present the discharge of itself. Table 2 presents the sensitivity parameters after adjusting to make the discharge from E54 and E92 Stations match one another the most. After comparing the discharge derived from the SWAT model with the data from Station E54 during 2008-2016 (9 years), the model demonstrated the annual average of 495.3 MCM which was higher than the result form the observed station where it was 446.1 MCM $($ RE average $=9.9 \%)$. At meantime, when compared with Station E92, the SWAT model showed the annual average of 984.3 MCM that was higher than the result from the observed station where it was $833.3 \mathrm{MCM}\left(\mathrm{RE}\right.$ average $=15.3 \%$ ). In case of using $\mathrm{R}^{2}$, the results from both E54 and E92 Stations were 0.86 and 0.91 (on average) respectively. This was similar to $\mathrm{E}_{\mathrm{ns}}$ where the results from both stations were 0.85 and 0.90 (on average) respectively. However, these results were still at a good rate of accuracy. The goodness of fit of a whole 9 years from E54 and E92 were also illustrated in Fig. 4(b)-(c).
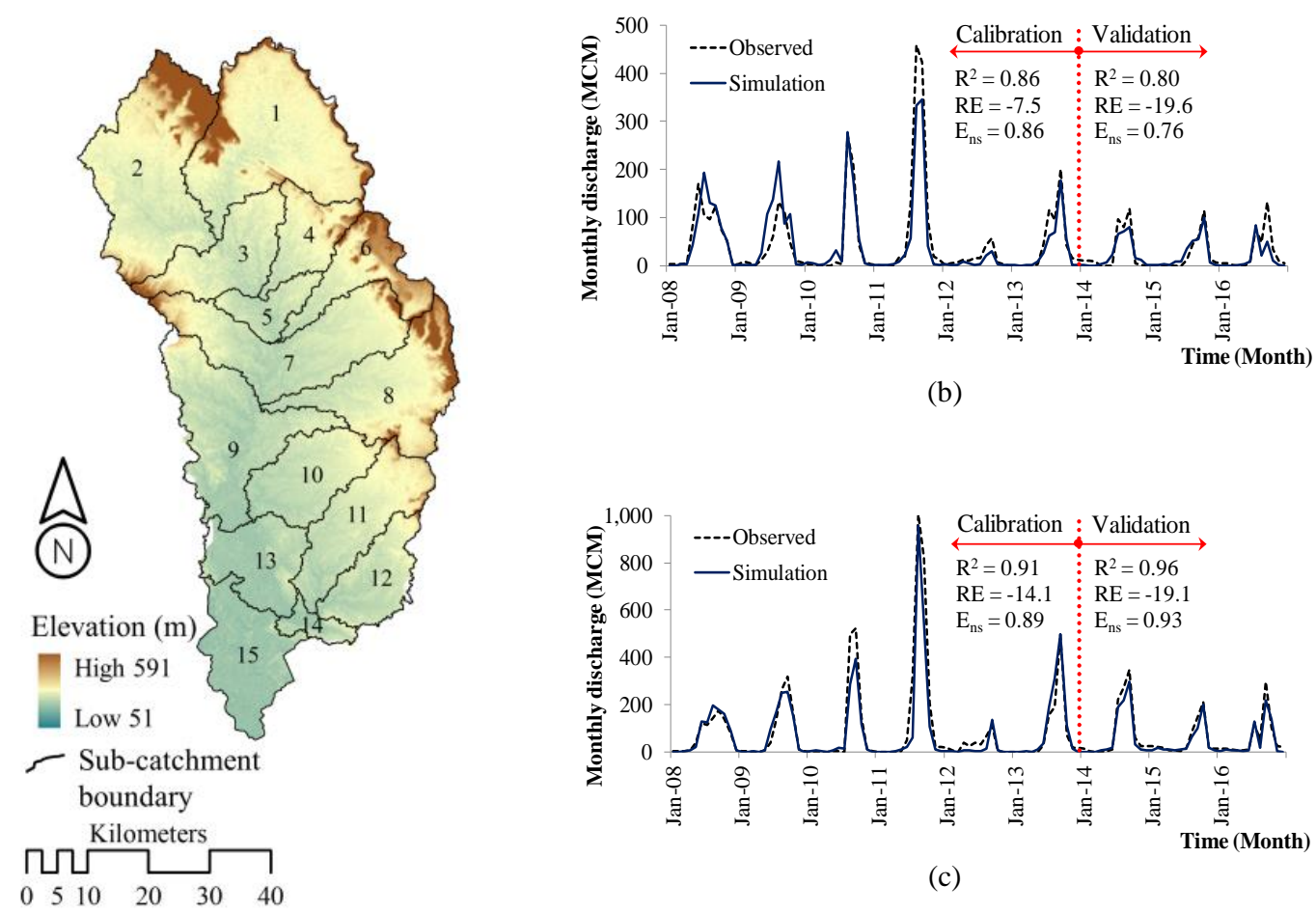

(b)

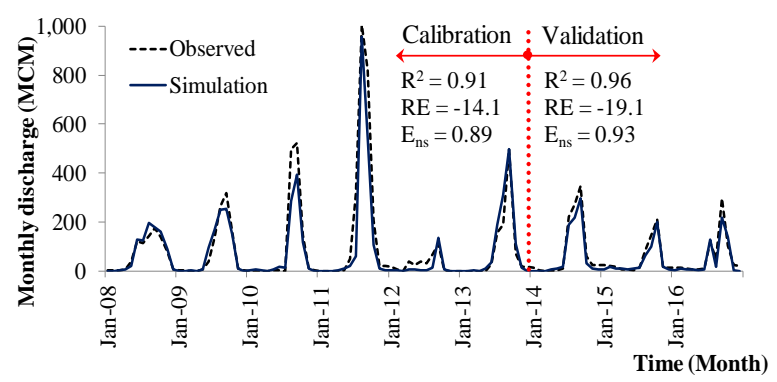

(c)

(a)

Fig. 4. SWAT simulation results, (a) 15 Sub-catchment in Yang Catchment, and discharge comparison between observed and simulation at (b) E54 and (c) E92.

Fig. 5 presents the monthly discharge of all 15 sub-catchments classified by the SWAT model after passing the verification method. The calculation results indicate the consistency with baseline year discharge from both observed stations. In the year 2008-2010, the value is close to the normal average and in 2011 has increased due to the period of high rainfall. The maximum discharge value will occur in the sub-catchment No.15, which is also the outlet point of the Yang Catchment, (the maximum discharge value was $642 \mathrm{MCM}$, occurring in 2011). In contrast, the result from 2012-2016 was lower than the average since the rainfall was decreased. After all, the monthly maximum discharges in each year were used to create the equations for Gumbel frequency distribution and flood 
frequency chart that was finally derived as the maximum flow rate equation to find the maximum flow rate of each return period.

Table 2.

SWAT final adjusted sensitivity parameters.

\begin{tabular}{|c|c|l|c|c|c|}
\hline No. & Parameter & \multicolumn{1}{|c|}{ Description } & Range & Before & Final \\
\hline 1 & SOL_AWC & Available water capacity & $0-1$ & 0.14 & 0.4 \\
\hline 2 & ESCO & Soil evaporation & $0-1$ & 0.95 & 0.85 \\
\hline 3 & ALPHA_BF & Base flow alpha factor & $0-1$ & 0.048 & 0.0001 \\
\hline 4 & SLSUBBSN & Average slope length & $0-150$ & 15.42 & 12.00 \\
\hline 5 & GW_DELAY & Groundwater delay time & $0.05-24$ & 2 & 30 \\
\hline 6 & SURLAG & Surface runoff lag coefficient & $0-0.30$ & 0.014 & 0.013 \\
\hline 7 & CH_N2 & $\begin{array}{l}\text { Manning's "n" value for the main } \\
\text { channel }\end{array}$ & & \\
\hline
\end{tabular}

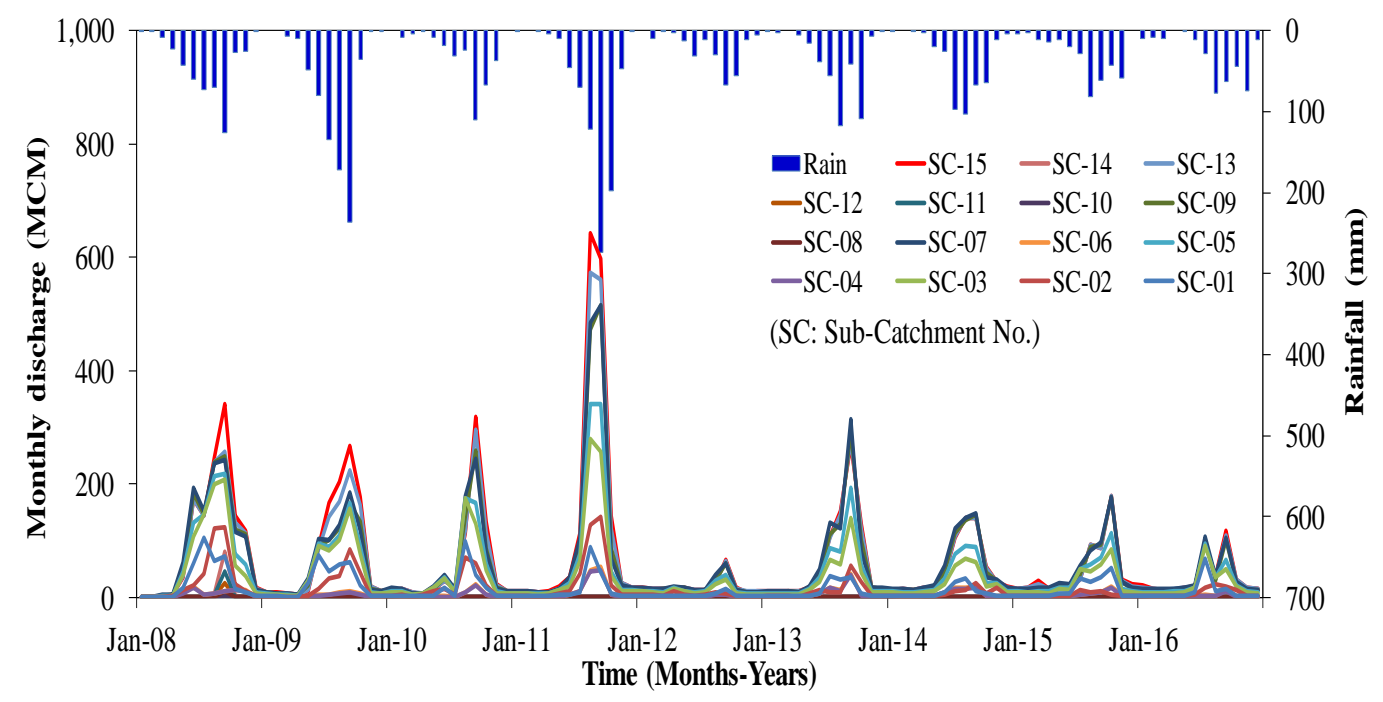

Fig. 5. Monthly discharge of 15 Sub-catchments.

\subsection{Maximum discharge by return period}

The Gumbel frequency distribution was conducted by finding a relationship between the maximum discharge from each of 15 sub-catchments through a whole 9 years derived from the SWAT model and the results were arranged in a descending order (' $y$ ' axis) and the return periods in a logarithmic scale chart (' $x$ ' axis). It was finally derived as the equation for the maximum discharge by each return period of all 15 sub-catchments. Particularly, this study considered the return period of 2 years, 5 years, and 10 years respectively (since the data was taken from 9 baseline years for the prediction equation, the return period should not be more than 10 years for accurate result). After all, the maximum discharges of all sub-catchments were presented in Table 3.

According to the maximum discharge of 15 sub-catchments derived from the equation in Table 3, the maximum discharges were increased following the return period of 2 years, 5 years, and 10 years respectively. Sub-catchment 15 was the one with the highest maximum discharge where the maximum discharges were 216.9, 428.6, and 588.7 MCM sequentially. This was followed by Subcatchment 13, 7, and 9 where the maximum discharges were decreased one by one. At meantime, Sub-catchment 10, 12, 11, and 14 demonstrated the least discharges ranged from $0.2 \mathrm{MCM}$ (for the 2-year return period) to $49.1 \mathrm{MCM}$ (the 10-year return period) sequentially. Significantly, by comparing the 9-year average maximum discharge of all sub-catchment from the SWAT model (as 
presented in a column 'Baseline' in Table 3), it was indicated that the results of the 5-year and 10year return periods were higher than the result from the SWAT model whereas the result from the 2year return period was slightly lower than the SWAT model's result.

Table 3.

Maximum discharge by the sub-catchment equation in return periods.

\begin{tabular}{|c|c|c|c|c|c|c|}
\hline \multirow{2}{*}{$\begin{array}{c}\text { Sub- } \\
\text { catchment } \\
\text { No. }\end{array}$} & \multirow{2}{*}{$\begin{array}{l}\text { Equations for calculate } \\
\text { the maximum discharge }\end{array}$} & \multirow[t]{2}{*}{$\mathbf{R}^{2}$} & \multicolumn{4}{|c|}{$\begin{array}{c}\text { Maximum discharge } \\
\text { by each return period (MCM) }\end{array}$} \\
\hline & & & Baseline & 2 year & 5 year & 10 year \\
\hline 1 & $y=40.853 \ln (x)+28.336$ & 0.872 & 64.3 & 56.7 & 94.1 & 122.4 \\
\hline 2 & $\mathrm{y}=66.17 \ln (\mathrm{x})+2.9875$ & 0.934 & 61.2 & 48.9 & 109.5 & 155.3 \\
\hline 3 & $y=105.61 \ln (x)+44.043$ & 0.967 & 137.0 & 117.2 & 214 & 287.2 \\
\hline 4 & $y=19.04 \ln (x)+4.2243$ & 0.947 & 21.0 & 17.4 & 34.9 & 48.1 \\
\hline 5 & $y=121.14 \ln (x)+53.064$ & 0.958 & 159.7 & 137 & 248 & 332 \\
\hline 6 & $y=20.739 \ln (x)+4.9219$ & 0.953 & 23.2 & 19.3 & 38.3 & 52.7 \\
\hline 7 & $\mathrm{y}=183.03 \ln (\mathrm{x})+61.088$ & 0.959 & 222.2 & 188 & 355.7 & 482.5 \\
\hline 8 & $y=3.9451 \ln (x)-2.1379$ & 0.617 & 1.3 & 0.6 & 4.21 & 6.95 \\
\hline 9 & $y=183.27 \ln (x)+57.563$ & 0.954 & 218.9 & 184.6 & 352.5 & 479.6 \\
\hline 10 & $y=1.2196 \ln (x)-0.6635$ & 0.608 & 0.4 & 0.2 & 1.3 & 2.1 \\
\hline 11 & $\mathrm{y}=16.173 \ln (\mathrm{x})-8.8479$ & 0.563 & 5.4 & 2.4 & 17.2 & 28.4 \\
\hline 12 & $y=8.8445 \ln (x)-4.8101$ & 0.566 & 3.0 & 1.3 & 9.4 & 15.6 \\
\hline 13 & $y=199.85 \ln (x)+60.247$ & 0.932 & 236.1 & 198.8 & 381.9 & 520.4 \\
\hline 14 & $y=27.951 \ln (x)-15.293$ & 0.564 & 9.3 & 4.1 & 29.7 & 49.1 \\
\hline 15 & $\mathrm{y}=230.99 \ln (\mathrm{x})+56.812$ & 0.942 & 260.1 & 216.9 & 428.6 & 588.7 \\
\hline
\end{tabular}

\subsection{Flood-risk area map at Yang Catchment}

Fig. 6 presents the map of the flood-risk area in each sub-catchment derived from the spatial data and classified by ArcGIS model. Fig. 6(a) shows the maximum discharge through a whole 9 baseline years (2008-2016) from the SWAT model while Fig. 6(b)-(c) illustrates the results from the return period of 2, 5, and 10 years. All results were discussed as follows.

4.3.1 2-Year return period: After comparing the regular maximum discharge (9 years) as seen in Fig. 6(b), it was found that Sub-catchment 1, 2, 4, 6, 8, 10, 11, 12, and 14 similarly demonstrated the results in a range from $0-100 \mathrm{MCM}$ which as the same as the regular average. The results from Subcatchment 3, 5, 7, 9, and 13 were in a range from 101-200 MCM and there were 3 sub-catchments showing lower results than the regular average including Sub-catchment 7, 9, and 13 (regular average was ranged from 201-300 MCM. However, Sub-catchment 15 presented the highest maximum discharge for the 2-year return period that was 216.9 MCM and this was very close to the regular average of $260.1 \mathrm{MCM}$ (16.6\% of data difference). Consequently, it was expected that Sub-catchment 15 was most possible to encounter the flood compared to other sub-catchments.

4.3.2 5-year return period: In case of the 5-year return period (see Fig. 6(c)), the flood-risk area was expanding from the 2-year return period or from 1 to 7 sub-catchments where the maximum discharges became higher than the regular average including Sub-catchment 2 showing in a range from 101-200 MCM (regular average was from 0-100 MCM), Sub-catchment 3 and 5 showing in a rage of 201-300 MCM (Regular average was from 101-200 MCM), and Sub-catchment 7, 9, and 13 showing in a range of 301-400 MCM (Regular average was from 201 -300 MCM). In addition, Subcatchment 15 still showed the highest maximum discharge of $428.6 \mathrm{MCM}$ which was $64.8 \%$ different from the regular average. Nevertheless, during this return period, there were 8 sub-catchments 
showing the results equal to the regular average (from 0-100 MCM) including 1, 4, 6, 8, 10, 11, 12, and 14 sequentially.

4.3.3 10-year return period: Based on the flood-risk distribution map during the 10-year return period (see Fig. 6(d)), the most flood-risk area has been expanded to 8 sub-catchments while the maximum discharge was also highly increased $19-52 \%$ compared to the regular average. This notably indicated that there were 4 sub-catchments where the maximum discharges had been increased including Subcatchment 7 and 9, (increased from 301-400 to 401-500 MCM and Sub-catchment 13 and 18 where it became higher than $500 \mathrm{MCM}$ ). During this 10-year return period, there still were 7 sub-catchments showing the results equal to the regular average (from 0-100 $\mathrm{MCM}$ ) including 4, 6, 8, 10, 11, 12, and 14 respectively.

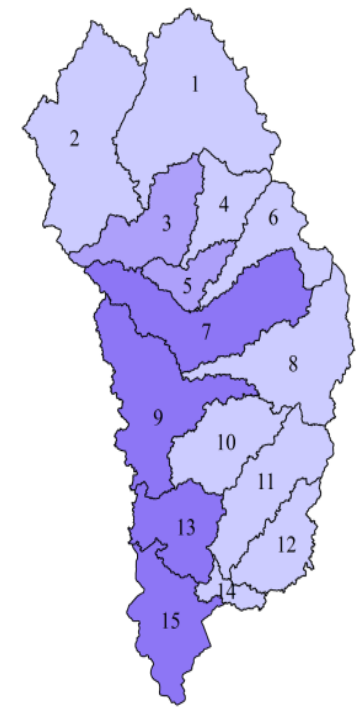

(a)

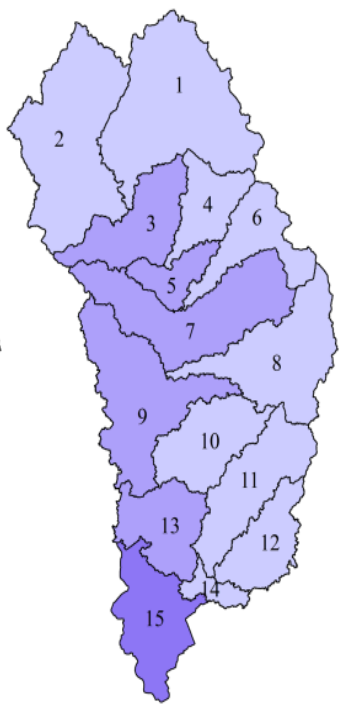

(b)

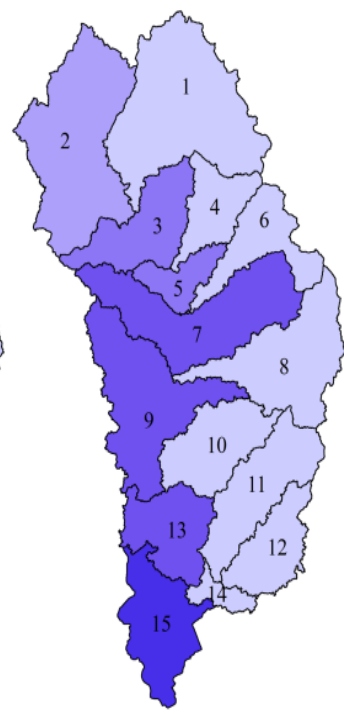

(c)

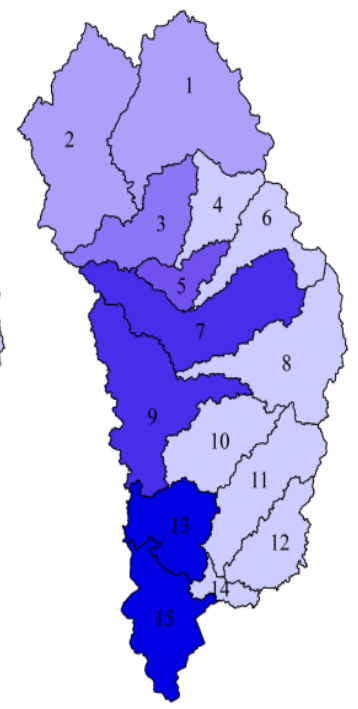

(d)

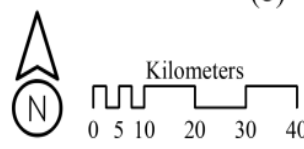

Maximum discharge range $(\mathrm{MCM})$

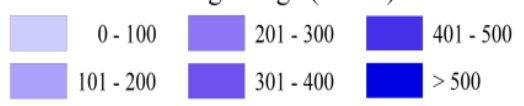

Fig. 6 Maximum discharge in sub-catchment area simulated from Gumbel distribution by each return period compare with the baseline year, )a) Average 9 baseline year, )b) 2-year return period, (c) 5-year return period, and (d) 10-year return period.

\section{CONCLUSIONS}

In this study, the flood estimation from the maximum discharge at Yang Catchment uses the SWAT model to classy the area into different sub-catchments and estimate the monthly maximum discharge in each year as well as using a Gumbel frequency distribution method to create the floodfrequency equations by the return period of 2 years, 5 years, and 10 years. Then, all of the results were presented as the flood-risk spatial map created by ArcGIS model and it was concluded that the SWAT model was able to classify the target area into 15 sub-catchments by the physical characteristics at each level of land contour. Moreover, it was found that when comparing the discharge estimation during 2008-2016 using the SWAT model with the data from 2 observed stations - E54 and E92, the result was satisfactory that could be affirmed by $\mathrm{R}^{2}, \mathrm{RE}$, and $\mathrm{E}_{\mathrm{ns}}$ that also allows the user to know the maximum discharge in each sub-catchment from the model.

Creating the flood frequency equation was a process of making the frequency distribution from the monthly maximum discharge in each sub-catchment derived from the SWAT model following 
Gumbel's theory. For the results, it was found in the 2-year return period that the maximum discharge was similar to the average maximum discharge ( 9 years) and it was increasing by years of the return period. Notably in the 10-year return period, the maximum discharge was $19-52 \%$ higher than the regular average. Additionally, for flood-risk area simulation in Yang Catchment, the maximum discharge in each return period were presented as the spatial map crated by ArcGIS model that was able to classify the extents and differences of the flood severity and possibility with different shades of colors for different return periods and maximum discharge derived from the equations in each subcatchment. After considering the flood-risk area from the map, most of the sub-catchments in the southwest (Sub-catchment 7, 9, 13, and 15) has higher possibility of flooding since the maximum discharges there are much higher than the regular average. Furthermore, the physical characteristics there were the lowland with many rivers crossing through, especially Sub-catchment 15 where it is the final outlet to Yang Catchment. On the contrary, the eastern zone has low possibility of flooding since the maximum discharge was similar to the regular average and most of the land is higher than the western zone.

This study is likely a tryout on both hydrological and metrological data that had been completely collected from the target area during 2008-2016 (totally 9 years) where it was used as an initial data. For the accurate result of data analysis, the data prediction in this study was not over 10 years. Hopefully, it was expected that complete data recorded in a longer term $(20-30$ years and more $)$ would provide the equation for maximum discharge estimation with more accurate results from more return periods e.g. 20 years, 50 years, or 100 years (It would probably provide more of the flood frequency map by the increasing return periods). Moreover, the future discharge estimation from different types of climate simulators together with a hydrological model could be another approach to predict the maximum discharge and create the flood-risk area map in the future. Above all, the researcher team hopefully expects that the research methodology and outcomes from this study would provide the useful data and be another channel to facilitate all stakeholders and any organizations within any river catchment areas to understand better about the hydrological processes in order to decrease the loss from the flood as well as be able to manage the sustainable water resources in the future.

\section{ACKNOWLEDGEMENT}

This research is supported by Faculty of Engineering, Rajamangala University of Technology Isan, Khon Kaen Campus. The data on discharge analysis were kindly provide by Royal Irrigation Office 6, Khon Kaen. The climate and spatial data were originally provided by Thai Meteorology Department and Land Development Department.

\section{R E F E R E N C E S}

Arnold, A.G., Srinivasan, R., Muttiah, R.S. \& Williams, J.R. (1998) Large area hydrological modeling and assessment pert I: model development. Journal of American Water Resource Association, 34(1), 73-89.

Asgharpour, S.E. \& Ajdari, B. (2011) A case study on season floods in Iran, watershed of Ghotour Chai Basin. Procedia - Social and Behavioral Sciences, 19, 556-566.

Begou, J.C., Jomaa S., Benabdallah, S., Bazie, P., Afouda A. \& Rode, M. (2016) Multi-site validation of the SWAT model on the Bani Catchment: model performance and predictive uncertainty. Water, 8(178), https://doi.org/10.3390/w8050178.

Bhagat, N. (2017) Flood frequency analysis using Gumbel's distribution method: A case study of lower Mahi Basin, India. Journal of Water Resources and Ocean Science, 6(4), 51-54.

Chung, S., Takeuchi, J., Fujihara, M. \& Oeurng, F. (2018) Flood damage assessment on rice crop in the Stung Sen River Basin of Cambodia. Paddy and Water Environment, https://doi.org/10.1007/s10333-019-007181. 
Fukunaga, D.C., Cecílio, R.A., Zanetti, S.S., Oliveira, L.T. \& Caiado, M.A.C. (2015) Application of the SWAT hydrologic model to a tropical watershed at Brazil. Catena, 125, 206-213.

Ganamala, K. \& Kumar, P.S. (2017) A case study on flood frequency analysis. International Journal of Civil Engineering and Technology, 8(4), 1762-1767.

Györi M-M., Haidu I., \& Humbert J., (2016). Deriving the floodplain in rural areas for high exceedance probability having limited data source. Environmental Engineering and Management Journal, 15(8), 18791887.

Haidu, I., \& Ivan, K. (2016). Évolution du ruissellement et du volume d'eau ruisselé en surface urbaine. Étude de cas : Bordeaux 1984-2014, France. La Houille Blanche, 5, 51-56.

Haidu, I., Batelaan, O., Crăciun, A.I., \& Domniţa, M. (2017). GIS module for the estimation of the hillslope torrential peak flow. Environmental Engineering and Management Journal, 16(5), 1137-1144.

Ivan, K., Gagacka, D. \& Matecka, P. (2018) Automated tool for the extraction of the surface ponds based on LiDAR data. Geographia Technica, 13(2), 89-96.

Kumar, N., Singh, S.K., Srivastava, P.K. \& Narsimlu, B. (2017) SWAT model calibration and uncertainty analysis for streamflow prediction of the Tons River Basin, India, using Sequential Uncertainty Fitting (SUFI-2) algorithm. Modeling Earth Systems and Environment, 3(30), https://doi.org/10.1007/s40808-0170306-z.

Lin, B.Q., Chen, X., Yao, H., Chen, Y., Liu, M., Gao, L. \& James, A. (2015) Analyses of land use change impacts on catchment runoff using different time indicators based on SWAT model. Ecological Indicators, 58, 5563.

Maghsood, F.F., Moradi, H., Bavani, A.R.M., Panahi, M., Berndtsson, R. \& Hashemi, H. (2019) Climate change impact on flood frequency and source area in Northern Iran under CMIP5 scenarios. Water, 11(273), https://doi.org/10.3390/w11020273.

Ning, J., Gao, Z. \& Lu, Q. (2015) Runoff simulation using a modified SWAT model with spatially continuous HRUs. Environmental Earth Sciences, 74, 5895-5905.

Olumide, B.A., Saidu, M., \& Oluwasesan, A. (2013) Evaluation of best fit probability distribution models for the prediction of rainfall and runoff volume (Case study Tagwai Dam, Minna-Nigeria). International Journal of Engineering and Technology, 3(2), 94-98.

Parhi, P.K. (2018) Flood management in Mahanadi Basin using HEC-RAS and Gumbel's extreme value distribution. Journal of The Institution of Engineers (India): Series A, 99(4), 751-755.

Pereiraa, D., dos R., Martinez, M.A., Pruski, F.F., \& de Silva, D.D. (2016) Hydrological simulation in a basin of typical tropical climate and soil using the SWAT model part I: Calibration and validation tests. Journal of Hydrology: Regional Studies, 7, 14-37.

Pinheiro, E.C. \& Ferrari, S.L.P. (2016) A comparative review of generalizations of the Gumbel extreme value distribution with an application to wind speed data. Journal of Statistical Computation and Simulation, 86(11), 2241-2261.

Sajikumar, N. \& Remya, R.S. (2015) Impact of land cover and land use change on runoff characteristics. Journal of Environmental Management, 161, 460-468.

Shrestha, S. \& Lohpaisankrit, W. (2017) Flood hazard assessment under climate change scenarios in the Yang River Basin, Thailand. International Journal of Sustainable Built Environment, 6, 285-298.

Strapazan, C. \& Petruţ, M. (2017) Application of ArcHydro and HEC-HSM model techniques for runoff simulation in the headwater areas of Covasna Watershed (Romania). Geographia Technica, 12(1), 95-107.

Subyani, A.M. (2011) Hydrologic behavior and flood probability for selected arid basins in Makkah area, western Saudi Arabia. Arabian Journal of Geosciences, 4(5-6), 817-824.

Swain S., Verma M.K., Verma M.K. (2018) Streamflow estimation using SWAT model over Seonath River Basin, Chhattisgarh, India. In: Singh V., Yadav S., Yadava R. (eds) Hydrologic Modeling. Water Science and Technology Library, 81, 659-665. 